\title{
Cogestão e neoartesanato: elementos conceituais para repensar o trabalho em saúde combinando responsabilidade e autonomia
}

\author{
Democratic management and new craft: concepts to rethink \\ integration between autonomy and responsibility in health work
}

Gastão Wagner de Sousa Campos ${ }^{1}$

Abstract This article analyses tensions between the dominant management rationality and health work. By means of philosophical concepts and bibliography revision it was found that clinical and public health practices are structured as praxis, a term defined by Aristotle. It does not work automatically, depending on a human being to reflect and decide in most situations, making mediation between established knowledgeand singular context. So, it is recommended the adoption of a management model that enables and favors the combination of professional autonomy and sanitary responsibility.

Key words Democratic management, Health work, $\mathrm{H}$ ealth and philosophy
Resumo Esteartigo discute tensões entre a racionalidade gerencial dominante e 0 trabalho em saúde. Valendo-se de conceitos da filosofia e de revisão de autores que estudaram o trabal ho em saúde, aponta-se que as práticas, clínicas e em saúde pública, são estruturadas conforme o conceito de práxis, definido por A ristóteles. Não funcionam mecanicamente e dependem de um sujeito mediador que reflita e tome decisões na maioria dos casos, alguém que estabeleça uma mediação entre o saber estruturado e o contexto singular. N esse sentido, recomenda-se a adoção de modelo de gestão que possibilite e favor eça a combinação de autonomia profissional com responsabilidade sanitária.

Palavras-chave Cogestão, Trabalho em saúde, Filosofia e saúde

\footnotetext{
${ }^{1}$ Departamento deM edicina Preventiva e Social, FaculdadedeCiências M édicas, Universidade Estadual deCampinas. Rua Tessália Vieira de Camargo 126, Cidade Universitária Zeferino Vaz. 13083-970 Campinas SP.

gastaowagnermpc.com.br
} 


\section{Racionalidade gerencial hegemônica}

Há vários anos, tenho investigado a hipótese de que a maioria dos métodos de gestão, desenvolvidos no século $X X$, tinha como estratégia, explícita ou implícita, a utopia de controlar absolutamente o trabalho humano". Denominei de "racionalidade gerencial hegemônica" as várias teorias ou métodos que buscam regular o trabalho do ser humano. Valendo-se de distintos recursos, se esforçam para aproximá-lo do funcionamento de uma máquina. Um mecanismo concebido em uma lógica mecânica ou cibernética, com essa finalidade foram criados tanto métodos de controle direto - supervisão -, quanto modos indiretos de controle, como a avaliação deresultados.

Por que haveria se conformado esta obsessão histórica com a moldagem da força de trabalho a padrões mecânicos de funcionamento? Por que os modelos de gestão pretendem, de modo sistemático, reduzir a autonomia do ser humano inserido em cadeias produtivas? Por que tal concepção transformou-se no modo hegemônico para se pensar e operar sistemas de produção de bens e serviços?

Há justificativas políticas, econômicas e científicas que sustentam essa racionalidade. Considero quehaja três elementos fundamentais que a constituem e justificam as pretensões de controle sobre o trabalhador. A primeira éa tendência a subordinar o trabal ho a modos de funcionamento padronizados a priori. Tenta-se reduzir o espaço para reflexão e decisão autônoma durante a execução das tarefas. A realização dessa estratégia dependeu de uma aproximação entre o discurso próprio da gestão com o discurso científico ${ }^{2}$. Não foi por acaso que o livro que funda essa perspectiva controladora denominouse de Princípios da administração científica, de autoria de Taylor ${ }^{3}$. Para a ciência de base positivista, seria possível, mediante a acumulação de evidências quantificáveis, construir-se padrõese normas que regulassem o trabalho em um determinado processo específico. Segundo essa concepção, somente os especialistas ou os dirigentes conheceriam "the best way" para construir-se alguma coisa. Entretanto, conforme apontaram vários autores ${ }^{4}$, essa tendência a esvaziar a capacidade de imagi nação, de criação e de decisão dos trabalhadores durante o trabaIho, funda-se em discursos racionais sobre a natureza do trabal ho humano. A postam em diminuir ao máximo a imprevisibilidade do trabalho ${ }^{5}$. Ricardo Antunes ${ }^{6}$ menciona a tendência contemporânea dos modelos de gestão, apesar de todo o discurso sobre qualidade total e função polivalente do operador, de priorizar o trabalho morto sobre o trabal ho vivo em ato, produzindo a "liofilização" do trabalhador e do seu trabalho (ressecamento de sua dimensão humana). Esforça-se para condicionar a rede produtiva a protocolos, que definiriam as condutas e comportamentos apropriados; essa é a meta buscada pela racionalidadegerencial contemporânea. Postura que indica uma maior confiança no saber previamente acumulado, e com base em evidências, do que no tirocínio dos trabalhadores. É evidenteque, com base em justificativas científicas, há todo um esforço histórico para reduzir o sujeito do trabalho a um instrumento funcional, a procedimentos definidos com antecedência. Alguns autores falam em "reificação" do trabalhador ${ }^{7}$, em mecanismos de controle para restringir a livre expressão de sua subjetividade, de seus valores e mesmo de sua experiência prévia. A racionalidadegerencial hegemônica persegue a utopia de reduzir o sujeito do trabaIho a um objeto, a um recurso maleável conforme o planejamento e programas definidos pela direção ou por "quem entende do assunto", em geral especialistas que pensam e planejam afastados do espaço onde se realiza o trabalho.

Uma segunda característica da racionalidade gerencial dominante, decorrente da pretensão anunciada acima, éa de pensar-se como um instrumento disciplinar, como um modo de controle sobre o trabalho em geral e sobre os trabaIhadores em particular. Para esse discurso, a democracia organizacional seria um contrassenso, um modo para produzir-se o caos, um caminho para a ineficiência eineficácia dos processos produtivos. Centralização normativa e descentralização executiva. Ao máximo, convocam-se trabalhadores para corrigirem erros nas linhas de montagem, sempre em acordo com o programa preestabelecido, sempre para repor o funcionamento "normal", sempre para atenderem-se aos protocolos, metas e diretrizes definidas al hures. Para al cançar-se esse objetivo de controle, a imaginação gerencial tem sido pródiga; ora recorreà truculência, ao poder de excluir os rebeldes, os inaptos; ora, busca socorro na psicologia, seleção detrabalhadores com personalidadeadequada à função, estratégias de sedução, treinamentos de novas sensibilidades funcionais ao espírito da organização e, ainda, em outra vertente, se vale da noção de "interesse", prêmios financei ros ou de status para os produtivos, etc. ${ }^{8}$. A democracia não éum el emento valorizado pelas várias teorias de administração, ainda que se a reco- 
mende para o mundo situado fora das empresas e organizações.

A terceira característica do discurso gerencial dominante é que as escolas ou teorias da administração tendem a adotar uma visão "essencialista" sobre a natureza humana, o ser humano tenderia a comportar-se segundo seu interesse imediato independente do contexto ou de sua história social. As correntes filosóficas que pensam o ser de modo mais complexo não lograram influenciar o discurso gerencial. Assim, o controle pretendido pelas escolas de administração não objetiva ampliar a solidariedade ou formar cidadãos cultos ereflexivos. Ao contrário, para a racionalidade gerencial hegemônica, o ser humano seria incapaz de funcionar autonomamentesempreque inserido em processos coletivos de trabalho; ou seja, com o fim do artesanato, com a introdução do trabalho em série, em linhas de produção, haveria se criado a necessidade de um cérebro coletivo, uma instância queadministrassea tendência à dispersão de pessoas tendentes a decidir segundo seu interesse individual (homo aeconomicus) ou conforme a tradição ${ }^{9}$. A racionalidade construída pelo pensamento gerencial apresenta-se, portanto, como um pensamento pragmático e operacional, uma racionalidade de ferro ordenada em função de alcançarem-se determinados re sultados - a qualidade de certos produtos, determinada produtividade. Daí, talvez, advenhaa persistência histórica da denominação de "recursos humanos", predominante no discurso gerencial, como uma referência tanto aos trabalhadores quanto ao seu potencial produtivo. Os seres humanos, quando trabalham, deveriam ser manipulados como um "recurso".

\section{Gestão edemocracia: uma contradição em termos?}

Seria possível escapar-se do dilema entre autonomia profissional e o estabelecimento de formas rígidas de controle, de padronização ou de normatização dos processos de trabalho? Seria possível por meio da autogestão das organizações pelos próprios trabalhadores, no limite, se alcançar o bem-estar comum? Estaríamos obrigados a optar entre uma visão ingênua e romântica, que imagina trabalhadores e organizações completamente autônomos, isentos de qualquer forma externa de controle e outra tradicional, ainda que cínica e pragmática, que considera a democracia institucional incompatível com o trabalho produtivo?
Karl M arx, na I deologia alemã ${ }^{10}$ - um dos rascunhos mais citados como bibliografia, ainda quando seu autor o tenha atirado em uma gaveta, já que não mereceria destino melhor do quea "crítica dos ratos"-, argumentou contra as concepções que pensam o ser humano em abstrato, como portador de características gerais independentes da história e das condições concretas de existência. Para ele, o ser humano teria potencialidades que poderiam ou não se realizar a depender da interação entreo próprio sujeito eseu contexto histórico esocial. Segundo essa lógica, pouco se poderia afirmar sobre os trabalhadores em geral; em princípio, os trabalhadores não estariam centralmente preocupados com a sobrevivência, com interesses corporativos, com a qualidade e bel eza de suas obras ou com as necessidades dos usuários. Segundo Marx, haveria que se averiguar, em cada contexto histórico, o modo de funcionamento concreto dos sujeitos, e mais, haverse-ia que os analisar como produtos e produtores de certa estrutura cultural, econômica esocial. A ordem econômica, social ecultural, bem como a história, os induziria ora ao corporativismo, ora a preocupar-se com a sua obra ou com a sociedade, ou com os usuários, etc. Entretanto, no Capital ou mesmo no M anifesto comunista, é possível se ler uma concepção sobre a classe operária bem menos dinâmica do que aquela de seus escritos de juventude. N essas duas obras, percebe-se 0 autor preso a uma determinação estrutural da natureza do ser humano: a classe operária, por sua posição no modo de produção capitalista, tenderia à solidariedade e, ao buscar sua própria libertação, liberaria também à maioria da sociedade. Os trabalhadores não teriam nada a perder a não ser suas cadeias ${ }^{11}$ !

Quando da constituição da Saúde Coletiva brasileira, havia uma predominância do pensamento estruturalista ou neoestruturalista entre os intelectuais críticos. Um modo de conceber a dinâmica social que chegou a imaginar o desaparecimento do sujeito e o apagamento do ser humano diante da força do instituído, do estruturado $^{12}$. Alguns explicavam a liquidação da autonomia humana pela força do mercado e da economia, outros, pela cultura ou pela tradição, vários, pelo poder do saber ou dos paradigmas epistemológicos; al guns atribuíram a instituição da sociedade de controle ao poder do Estado ou de uma rede de micropoderes ${ }^{13}$.

Entretanto, tendo a concordar com a concepção expressa na I deologia alemã; há evi dências de que os seres humanos são ativos, reflexivos e modificam as condições que os condicionaram, 
reagem ao domínio do estruturado, produzindo espaços singulares de existência. Trabal ho com a concepção de que o ser humano é potente para coproduzir situações e contextos, algo próximo ao descrito por M arx. Valeria discutirem-se, em outra oportunidade, os elementos de proximidade e os desacordos entre essa compreensão do ser humano e, portanto, do ser humano enquanto trabal hador eo conceito de "ser aí" (daisen) de Heidegger ${ }^{14}$. As perguntas formuladas a partir da idéia dequenos coproduzimos, entrea iniciativa do sujeito e o condicionamento do mundo, são instigantes: como se conformará um médico generalista na atenção básica brasileira? 0 que é o "ser aí" do enfermeiro em um contexto concreto? 0 que é pensar sobre uma equipe como produto e produtora de uma história concreta - seres dependentes e agentes, ao mesmo tempo, moldados pela universidade, origem social, aspirações profissionais, modelo de gestão etc., mas capazes de reagir e de alterar alguns destes moldes estruturais?

Enfim, adotando-se tal concepção dinâmica sobre o modo de ser dos humanos, bem como do trabalhador em particular, instaura-se um profundo desconforto, lógico e ético, ante o discurso gerencial hegemônico. Que modo de gestão seria compatível para ordenar processos em que seres humanos estão envolvidos? Como estabelecer algum grau de ordem, de padronização, de controle, sem massacrar a capacidade de reflexão e os espaços para tomada de decisão daqueles imersos na tarefa de produzir saúde? Enfim, partindo-se destes pressupostos, caberia o desafio de inventarem-se organizações que levem em consideração a relação entre estrutura e sujeito. Como fazer isto sem a compreensão do sujeito e de seus atributos, entre eles o trabalho, sem investigar sobre sua conformação histórica, isto é, sobre o modo como foram coproduzidos, sobre a genealogia concreta de sujeitos concretos? Como formar médicos, enfermeiros, psicólogos, no Brasil? Por que uma parte se dirigiu para atenção básica, para o SUS? Seria possível gerenciar o trabalho em saúde levando em conta a complexidade destas relações?

Estas indagações fazem eco a uma afirmação de $M$ ichel Foucault, que, ainda no final dos anos setenta, reconhecia não haver sido inventado durante o século XX, quer no socialismo ou em sistemas públicos, uma "governomentalidade" (um modo de governar seres humanos) distinta daquela tradicional, desenvolvida pelo capitalismo ao longo dos séculos XIX eXX ${ }^{15}$.
Tensão estrutural e política entre o trabalho em Saúde ea racionalidade gerencial hegemônica

Parto do pressuposto que o trabalho em saúde tem algumas peculiaridades que ampliam a tensão entrea racionalidade gerencial hegemônica e o desenvolvimento das potencialidades do ser humano.

Aristóteles distinguia o saber humano em duas modalidades: o teorético ou contemplativo e 0 saber prático. 0 saber prático é aquele conhecimento produzido a partir da ação ou do agir humano. 0 saber prático poderia ser classificado em doistipos: técnica epráxis. A técnica seriaaquela atividadehumana em queo conhecimento prévio, estruturado, dispensaria o agente de qualquer reflexão, deliberação ou escolha em ato, ou seja, durante a execução de certo trabalho ${ }^{16}$. Um marceneiro constroi uma mesa definindo o modelo da mesa a priori, ele teria que ser valer de "técnicas" conhecidas e aplicá-las tendo em vista o diagnóstico sobre o tipo de madeira, instrumentos disponíveis e o desenho do objeto previamente elaborado. Ao contrário, a práxis seria aquela atividade humana em que o saber prévio, trabal ho morto acumulado (diria M arx) não isenta 0 agente da necessidade de uma reflexão prudente (diria Aristóteles) durante a execução da atividade ou do trabalho em questão. Na práxis, o agente da ação, ademais do planejamento pré vio com base no saber acumulado, deverá considerar o contexto singular em que sua ação se realiza: outros sujeitos envolvidos, valores, circunstâncias históricas, etc. A ética, a política, a justiça estariam, para Aristóteles, nessa categoria ${ }^{17}$.

Ora, me parece ser essa exatamente a descrição da modalidade de trabal ho a ser exercida pelo clínico ou pelo sanitarista ao elaborar um projeto de intervenção para enfrentar uma epidemia ou endemia em um contexto histórico singular. Klíno (clínica), em grego, refere-seà necessidade do médico inclinar-se sobre o paciente. N esse sentido, tento a interpretar essa denominação para o trabalho médico como um reconhecimento de que o profissional deveria sustentar uma posição inclinada (nem vertical ou horizontal) entre o saber médico dos compêndios e o sujeito enfermo, restrito a um leito ou a uma cadeira. A posição vertical indicaria uma prática técnica, incapaz de reconhecer a singularidade de cada caso, a variabilidade da ordem genérica (doença enquanto um ser, uma ontologia) encarnada em um indivíduo. Assumir a posição horizontal, o médico acostado junto ao paciente, por outro 
lado, indicaria um abandono do lugar profissional e assunção da função de cuidado familiar, lugar do amigo ou do parente.

Considero, portanto, o trabalho em saúde uma práxis. Como em toda práxis, é impossível operar-se sem algum grau de saber acumulado, sem teoria, método etécnicas previamente expe rimentados. Entretanto, caberia ao profissional, à equipe responsável por cada caso clínico ou sanitário, construir um novo modo de agir com base tanto no saber estruturado, quanto também no diagnóstico da situação específica e em valores do sujeito ou da cultura; ou seja, Ihe caberia adaptar o saber tecnológico ao contexto singular. Os métodos sugeridos para a elaboração de projeto terapêutico singular ou de projeto de intervenção partem destas considerações ${ }^{18}$. Óbvio que há procedimentos médicos, parcelas do trabalho em saúde, que se aproximam do trabalho técnico. A realização de um determinado procedimento cirúrgico, uma vez definido um diagnóstico e um projeto terapêutico, guarda analogia com a prática técnica. Entretanto, caso ocorra algum imprevisto durantea cirurgia, uma queda de pressão, a descoberta de uma anomalia congênita, a evidência de uma comorbidade, um sangramento, em qualquer destes casos, 0 profissional, a equipe, estarão obrigados a refletir e a tomar decisões não previstas no padrão técnico. Estratégias para controlar uma epide mia deaids, ou de dengue, dependerão do estado da arte, de conhecimentos estruturados com base em experiências eevidências anteriormenteverificadas; contudo, deverão ser modificadas em acordo à singularidade do território e da população a ser protegida.

Observe-se que o exercício do trabalho, segundo a lógica da práxis, depende desujeitos trabalhadores com importante grau de autonomia e de responsabilidade com o outro e com as instituições. Conforme demonstrei, a racionalidade gerencial dominante aposta em outra direção, buscando, em suas várias vertentes, restringir as situações em que o processo de trabalho depende de decisão autônoma dos trabalhadores.

Vários autores têm demonstrado a tendência do trabalho em saúde, particularmente do trabalho médico, constituir-se como tecnologia pura $^{19}$. De fato, a especialização, a fragmentação do trabalho clínico e o esforço político da racionalidade gerencial são forças que dificultam a práxis clínica ou sanitária.

A tese defendida nesse artigo é diferente. Argumento sobre a necessidade de se respeitar essa característica estrutural do trabalho em saúde - a práxis, buscando-se modelos de gestão que combinem autonomia, necessária para a práxis, com controle sobre o trabalho, considerando-se o saber estruturado, valores políticos e direitos dos usuários. Outros autores reconhecem haver dificuldade em subordinar o trabalho em saúde, particularmente aquele do médico, à lógica da gestão ${ }^{20}$. Escritores da corrente estruturalista atribuem essa dificuldade ao fato do profissional de saúde deter, quase em regime de monopólio, 0 controle sobre o saber fazer em saúde. Isto Ihes asseguraria autonomia relativa ao executarem ações clínicas e, em consequência, dificultaria o controle da gestão sobre o trabalho em saúde, particularmenteaquele denatureza clínica ${ }^{21}$. Ainda que este argumento deva ser levado em conta, seria importante assinalar que há outras áreas do trabalho profissional em que o saber especializado équase exotérico e, mesmo assim, houve enquadramento dos processos detrabal ho a protocolos e sistemas de monitoramento.

Há uma importante linha de pensadores da Saúde Coletiva que tem se valido da filosofia eda ciência social para compreender e a intervir sobreo trabal ho em saúde. Particularmente, há uma tradição investigativa sobre o trabalho médico e sobre o exercício da clínica. Uma estudiosa pioneira desse tema foi a professora M aria Cecília F. Donnangelo (1975) que, em seu livro M edicina e Sociedade ${ }^{22}$, apresentou uma série de inferências sobre modificações na prática desses profissionais. Professora D onnangelo procurou averiguar se, com as transformações no modo de produção da atenção a saúde no Brasil, ocorria subordinação do trabalho liberal quando de sua inserção em empresas (hospitais e clínicas) de capital privado ou estatal. Ela identificou que havia médicosliberais clássicos, pequenos produtores autônomos, e que emergia, no cenário da época, com grande força, tanto médicos proprietários (empresários), ainda que em pequeno número, quanto uma mai oria de assalariados em organizações públicas ou privadas. Entretanto, para sua surpresa, ela constatou que mais de dois terços dos médicos investigados trabal havam em uma forma estranha a essa classificação clássica. A essa quarta forma de inserção no mercado de trabaIho ela denominou de "autonomia". Formas de realizar a clínica que [...] poderiam ser consideradas intermediárias ou transacionais entre o liberal e 0 assalariado, na medida que envolvem um controle parcial dos meios de trabal ho ou da clientela [...].

Entretanto, tanto a professora Donnangelo quanto Ricardo Bruno ${ }^{23}$ consideraram esse esti- 
lo de prática profissional como "categoria residual"; ou seja, como uma modalidade de trabaIho tendente a desaparecer, quer nas empresas privadas, quer nos modernos sistemas de saúde. Em minha tese de mestrado, Os médicos e a política de saúde ${ }^{24}$, analisei esse fenômeno de outra forma. Considerei que os médicos se valeram da ação política, sindical e corporativa para defender essa autonomia relativa mesmo em situações em que não eram proprietários dos meios de trabalho. Ainda mais, constatei que, em muitos casos, em quase todo o trabalho hospitalar, por exemplo, os médicos conseguiram impor essa forma de organizar a atenção aos gestores. 0 conceito e a organização do trabal ho segundo a lógica de corpo clínico, em hospitais públicose privados, confirmam essa hipótese.

Além da luta política em defesa da autonomia, considero que haja duas características do trabalho em saúde que permitiram a conservação de autonomia relativa para médicos e outros profissionais de saúde. A primeira éa complexidade do processo saúde, doença e intervenção, fato que ganhou divulgação após a crítica ao paradigma biomédico elaborada pela Saúde Coletiva e promoção à saúde. Em alguma medida, na prática, não somente ao se lidar com casos crônicos, mas em muitas outras situações, tem se tornado difícil não incorporar o usuário como pessoa, ficando-se tão somente com a doença como objeto da clínica (dimensão psicossocial). A segunda característica estrutural que propicia contexto favorável à essa autonomia relativa das equipes de saúde é a variabilidade do processo saúde e doença, gerando a relação paradoxal entre padronização e singularidade dos casos (no espaço e no tempo).

\section{Cogestão eneoartesanato em saúde:} a democracia necessária?

Poderemos considerar, portanto, que haja singularidade dos casos no trabalho em saúde, o queexigeimprovisação ecriatividadeem ato: clínica da fusão de paradigmas e de protocolos. A prática em saúde assemelha-se, portanto, mesmo quando realizada em equipe ou em rede, ao trabalho artesanal, um neoartesanato ainda a ser desenvolvido em sua plenitude. 0 que dependerá da construção de modelo de gestão do trabaIho segundo lógica não maquínica ou burocrática. Ao contrário, haveria que se superar o malestar histórico entre gestão ea clínica, incômodo que se explica pela tradição (neo)taylorista de controle sobre a clínica e pela insistência em se retirar o poder de decisão do clínico eda equipee deslocá-lo para o protocolo, ou para al gum gestor, ou para um regulador situado ao final de um redeinformatizada ${ }^{25}$, conforme sugerido por várias escolas de gestão, particularmente pela denominada de managed health care $^{26}$.

A construção deoutra racionalidade gerencial em saúde dependerá de uma reconstrução crítica em vários planos, o da política, da sociabilidade, da gestão e mesmo da epistemologia. D entro disto, esse artigo defende a necessidade de também gestar-se outro paradigma para a gestão em saúde. Um paradigma que reconheça e conviva com a autonomia relativa dos trabalhadores, mas que desenvolva formas de controle sobre o trabalho segundo a perspectiva dos usuários e também tomando em consideração o saber estruturado sobre saúde. Há vários pesquisadores investigando e experimentando reformas no processo de produção de conhecimentos e no trabalho em saúde. A construção de um novo paradigma em gestão beneficiou-se bastante com o esforço para articular saberes sobrea subjetividade com temas ligados ao trabal ho em saúde ${ }^{27}$. Vale também ressaltar o esforço para introduzir a razão e 0 agir comunicativos habermasianos na gestão eno planejamento ${ }^{28}$ em saúde. A política do M inistério da Saúde denominada de Humaniza-SUS, em larga medida, busca trazer para o Brasil esse novo modo de pensar a gestão e o trabal ho em saúde ${ }^{29}$. Insere-se dentro desse movimento, voltado para a construção deuma nova racionalidadegerencial, que valorize a autonomia dos trabalhadores e usuários, a discussão sobre clínica ampliada ${ }^{30} \mathrm{e}$ sobre a busca da integral idade e de novas formas de cuidado no trabal ho em saúde ${ }^{31}$.

Parece-me que a incorporação destes novos conceitos depende de reformas organizacionaise também do processo de trabalho voltadas para ampliar a democracia institucional. É nesse sentido que venho sugerindo a adoção de sistema de cogestão e de apoio institucional; ou seja, reformas que concretizem formas de poder compartilhado entregestor e equipe, entre clínico eequipe, entre profissionais e usuários. Há al guns conceitos e arranjos organizacionais que possibilitam - não garantem - a cogestão do trabalho em saúde. Entreeles, vale destacar o esforço para se combinar graus autonomia dos profissionais com definição explícita de responsabilidadesanitária. Segundo essa perspectiva, o planejamento, a avaliação e, mesmo, eventuais contratos de metas dever-se-ão realizar de modo participativo e com apoio institucional. 
Ao contrário do que recomenda a racionalidade gerencial dominante, seria conveniente assegurar à equipe de referência responsável pelo caso a condução do projeto terapêutico, com a indicação de internação, acesso a exames ou a especialistas; ou seja, o grosso da "regulação" deveria depender da equipe, reservando-se aos "reguladores" papel de ordenação e de coordenação. Dentro dessa lógica, a construção de diretrizes, protocolos e campos de cuidado obedeceriam a estratégicas dialógicas de busca de consenso e envolvimento das equipes (agir comunicativo e cogestão). 0 novo modelo de gestão sugere que usuários e clínicos façam parte da gestão em todas suas etapas, ainda que com papel distinto dos administradores. Assegurar também ao paciente/usuário a condição de sujeitos com autonomia e poderes relativos: cogestão do projeto terapêutico; almejar-se não somente a produção de saúde, mas também considerar a autonomia do usuário como critério de qualidade (antídoto contra medicalização, consumismo e dependência).

Há alguns elementos operacionais conhecidos eque possibilitam tanto a cogestão quanto a ampliação da clínica edo trabalho em saúde. Para possibilitar o neoartesanato no trabal ho em saúde, sem desprezar a tradição dos Sistemas N acionais de Saúde, seria importante armarem-se mecanismos que assegurem relação usuário e profissional diacrônica (horizontal no tempo), estimulando a construção de vínculo e corresponsabilidade terapêutica ${ }^{32}$. A tradição conceitual dos sistemas nacionais de saúde, sintetizada no Relatório Dawson, recomenda que a definição do encargo (responsabilidade) sanitário para cada serviço ou equipe deverá ocorrer com relação a pessoas e território ${ }^{33}$.

Há ainda algumas estratégias organizacionais que permitem atenuar os efeitos destrutivos da fragmentação do trabalho em saúde:

- Profissional de referência: coordenador de caso e responsável pelo projeto terapêutico;
. Equipe de referência (espaço interprofissional): célula do modelo de gestão - deslocamento de parte do poder das corporações para equipes;

. Equipe interdisciplinar de apoio matricial: responsável por atenção à saúde a um conjunto de pessoas e território;

- Integração entre equipe de referência e apoio matricial: organizar trabalho compartilhado mediante: (1) atendimento conjunto decasos; (2) atendimento pelo especialista econtato com equipeque defineseguimento complementar; (3) troca deconhecimentos ede orientações diálogo sobre projetosterapêuticos entreapoio eequipee (4) busca de mecanismos para personalizar a relação entre profissionais der eferência econtrarreferência, estimuIando contato direto entre referência e apoio;

. Unidade de produção: departamentos dos serviços de saúde organizados segundo lógica interdisciplinar e modo de produção da atenção à saúde (processo de trabal ho, objeto e objetivos comuns); com essa lógica, se busca saltar do departamento corporativo ao departamento temático einterdisciplinar;

- Apoio Paidéia como metodologia para a cogestão da clínica: coconstruir capacidade deanálise/compreensão sobre si mesmo (saúde e doença) e sobre relações com o mundo da vida. Ampliar capacidade deintervenção sobresi mesmo e sobre organizações e contexto. Com esse objetivo, há al guns el ementos metodológicos do apoio Paidéia a ser considerados, tais como combinar ofertas provenientes do saber sanitário com demanda/interesse e valores do usuário; buscar a construção dialógica de um projeto terapêutico ou de intervenção; procurar analisar objetos de investimento enecessidades sociais do sujeito ou do coletivo, sentido e significado para o projeto de atenção. 0 método de apoio constroi-se com centralidade mediante a reflexão sobre a prática: falar sobre dificuldades da prática, em geral, tende a produzir uma abertura da resistência dos sujeitos e a busca de outras disciplinas, valores e possibilidades subjetivas ${ }^{34}$. 


\section{Referências}

1. Campos GWS. U m método para análise e co-gestão São Paulo: Hucitec; 2000.

2. Coriat B. El taller y El cronómetro: ensayo sobre El taylorismo, El fordismo e La producción en masa. M exico: Siglo Veintiuno Editores; 1992.

3. Taylor F. Princípios da administração científica. São Paulo: Atlas; 1960.

4. Motta FCP. Teoria geral da administração. São PauIo: Livraria Pioneira Editora; 1987.

5. Vieira M M F, Oliveira LMB. Administração contemporânea: perspectivas estratégicas. São Paulo: Atlas; 1999.

6. Antunes R. As formas de padecimento no trabalho. Saúde soc. 2008; 17(4):7-10.

7. Bottomore T. Dicionário do pensamento marxista. Rio de Janeiro: Jorge Zahar; 2001.

8. Lodi LB. História da administração. São Paulo: Pioneira; 1976.

9. Locke JB. Ensaio sobre o entendimento humano. Lisboa: Fundação Calouste Gulbenkian; 1999.

10. Marx K, Engels F. A ideologia alemã: crítica da filosofia alemã. São Paulo: M artins Fontes; 1974.

11. Marx K. O Capital: crítica da economia política. Vol. 1. São Paulo: Abril Cultural; 1985.

12. Carvalho Al. Da Saúde Pública às políticas saudáveis: saúde e cidadania na pós-modernidade. Cien Saude Colet 1966; 1(1):104-121.

13. Dosse F. História do estruturalismo. Vol. 1 e 2. São Paulo: Ensaio; 1993.

14. Heidegger M. Introdução à Filosofia. São Paulo: M artins Fontes; 2008.

15. Foucault M. Nascimento da biopolítica. São Paulo: M artins Fontes; 2008.

16. Aristóteles. Ética a Nicômaco. 2a ed. Bauru: EDIPRO; 2007.

17. Chaui M. Convite à Filosofia. São Paulo: Ática; 2009.

18. Campos GWS, Guerrero A. M anual de atenção básica: clínica ampliada e compartilhada. São Paulo: Hucitec; 2009.

19. Schraiber LB. 0 médico e sua interações: a crise dos vínculos de confiança. São Paulo, Hucitec; 2008.

20. Cecilio LCO. A morte de Ivan Ilitch, Leon Tolstoi: elementos para se pensar as múltiplas dimensões do cuidado em saúde. Interface (Botucatu) 2009; 13(1):4555.

21. Motta FP. Teorias da administração: alcances, limites e perspectivas. São Paulo: FGV; 1990.

22. Donnangelo MCF. M edicina e sociedade. São Paulo: Pioneira; 1975.
23. M endes-Gonçalvez RB. M edicina e História: Raízes sociais do trabalho médico [dissertação]. São Paulo (SP): Departamento de Medicina Preventiva, Faculdade de Medicina da Universidade de São Paulo; 1979.

24. Campos GWS. Os médicos e a política de saúde. São Paulo: Hucitec; 1988.

25. Richard SW, Ruef M, Mendel PJ, Caronna C. Institutional change and health organizations: from professional dominance to managed care. Chicago: The University of Chicago Press; 2000.

26. Kongstvedt PR. The managed health care handbook. $4^{\text {th }}$ ed. New York: Aspen Publishers; 2001.

27. Campos RTO. O encontro do trabalhador-usuário na atenção á saúde: uma contribuição da narrativa psicanalítica ao tema. Cien Saude Colet 2005; 10(3):573-583.

28. Rivera FJU, Artmann E. Planejamento e gestão em saúde: flexibilidade metodológica e agir comunicativo. Cien Saude Colet 1999; 4(2):355-365

29. Brasil. Ministério da Saúde. Cartilha PNH - Gestão Participativa e Co-gestão. Brasília: M inistério da Saúde; 2004.

30. Cunha GT. A clínica ampliada na atenção primária. São Paulo: Hucitec; 2005.

31. Ayres JRCM. Cuidado e reconstrução das práticas de saúde. Interface (Botucatu) 2004; 8(14):73-91.

32. Starfield B. Atenção primária: equilíbrio entre necessidades de saúde, serviços e tecnologia. Brasília: Unesco/M inistério da Saúde; 2002.

33. Dawson B. Informe Dawson sobre el futuro de los servicios médicos y afines - 1920. Washington, D.C.: OPS; 1964.

34. Campos GWS, Domitti AC. Apoio matricial e equipe de referência: uma metodologia para gestão do trabalho interdisciplinar em saúde. Cad Saude Publica 2007; 23(2):399-407.

Artigo apresentado em 29/04/2010

Aprovado em 18/05/2010

Versão final apresentada em 31/05/2010 